\title{
Identification and Characterization of Downy Mildew-Responsive microRNAs in Indian Vitis vinifera by High-Throughput Sequencing
}

\author{
Milan V. Kamble ${ }^{1}$, Abhishek B. Shahapurkar ${ }^{1}$, Shivakantkumar Adhikari ${ }^{1}$, Nagaraja Geetha ${ }^{2}$, Asad Syed ${ }^{3}$, \\ Bilal Ahmed ${ }^{4}$ (D) and Sudisha Jogaiah $1, * \mathbb{D}$
}

1 Laboratory of Plant Healthcare and Diagnostics, PG Department of Studies in Biotechnology and Microbiology, Karnatak University, Pavate Nagar, Dharwad 580003, Karnataka, India; milankamble115@gmail.com (M.V.K.); abhishekshahapurkar09@gmail.com (A.B.S.); adhikariklr93@gmail.com (S.A.)

2 Nanobiotechnology Laboratory, Department of Studies in Biotechnology, University of Mysore, Mysore 570005, Karnataka, India; geethabiotech.uom@gmail.com

3 Department of Botany and Microbiology, College of Science, King Saud University, Riyadh 11451, Saudi Arabia; assyed@ksu.edu.sa

4 School of Chemical Engineering, Yeungnam University, Gyeongsan 38541, Korea; bilal22000858@yu.ac.kr

* Correspondence: jsudish@kud.ac.in; Tel.: +91-836-2779533; Fax: +91-836-2747884

Citation: Kamble, M.V.; Shahapurkar, A.B.; Adhikari, S.; Geetha, N.; Syed, A.; Ahmed, B.; Jogaiah, S. Identification and Characterization of Downy Mildew-Responsive microRNAs in Indian Vitis vinifera by HighThroughput Sequencing. J. Fungi 2021, 7, 899. https://doi.org/ 10.3390/jof7110899

Academic Editors: Sengottayan Senthil-Nathan and Jae Su Kim

Received: 22 September 2021 Accepted: 21 October 2021

Published: 25 October 2021

Publisher's Note: MDPI stays neutral with regard to jurisdictional claims in published maps and institutional affiliations.

Copyright: (c) 2021 by the authors. Licensee MDPI, Basel, Switzerland. This article is an open access article distributed under the terms and conditions of the Creative Commons Attribution (CC BY) license (https:// creativecommons.org/licenses/by/ $4.0 /)$.

\begin{abstract}
Downy mildew (DM) is one of the most devastating diseases disturbing viticulture, mainly during temperate and humid climates. The DM pathogen can attack grapevine leaves and berries differentially, and the disease is managed with recurring applications of fungicides that direct pathogen pressure, develop of resistant strains, and lead to residual soil toxicity and increased pollution effects. Plant microRNAs (miRNAs) are important candidates in physiological regulatory roles in response to biotic stress in plants. In this study, high-throughput sequencing and MiRDeep-P were employed to identify miRNAs in Vitis vinifera. Altogether, 22,492,910, 25,476,471, and 22,448,438 clean reads from the sterile distilled water (SDW)-control, bio-pesticide Trichoderma harzianum (TriH_JSB36)-treated, and downy mildew Plasmopara viticola pathogen libraries, respectively, were obtained. On the basis of the sequencing results and analysis (differential expression analysis), we observed significant differences in 15 miRNAs (5 novel upregulated, and 10 known downregulated) in the pathogeninfected sample (Test) in comparison to the SDW-control sample, with majority of the reads beingin the range of 20-24 bp. This study involves the identification and characterization of vvi-miRNAs that are involved in resistance against downy mildew disease in grapes.
\end{abstract}

Keywords: grapevine; Vitis vinifera; downy mildew; Plasmopara viticola; microRNA; qRT-PCR

\section{Introduction}

Grapevine (Vitis vinifera L.) is one of the most widely cultivated fruit crop with global economic significance. Wine production is greatly dependent on grapevine species and hence it is well acknowledged to mankind along with its mouth-watering juice. In India, the total cultivation of grapevine is about 34,000 hectares, and the total annual production is $1,000,000$ tons per year [1]. The successful cultivation of grapevine suffers due to the attack of number of diseases, and hence appropriate plant management practices is of utmost importance in obtaining desired production levels. The disease-causing pathogen and the host encompass a dynamic relationship that can change with time. For the appropriate and feasible management, it is important to study the disease epidemiology and to understand the adaptation and variability of the DM pathogen to get a deeper insight into its life cycle.

The different varieties of $V$. vinifera cultivated worldwide are susceptible to various pathogens and are the reason for severe crop losses, including the oomycete Plasmopara viticola, the causal agent of the DM disease. Oomycetes are eukaryotic organisms with 
characteristics of fungus; they are unique that belong to the Stramenopiles, which also include the brown algae and diatoms. Oomycetes include terrestrial, freshwater, and marine organisms, but they are mainly pathogenic to plant and animals [2]. These pathogens cause many diseases in plants and animals causing huge impacts. In animals, Saprolegniosis mostly affects freshwater fishes, and the other notorious oomycete diseases include sudden oak death, white rust, potato late blight, and downy mildew in many plant species. Deeper studies related to the understanding of the oomycete pathogens virulence patterns and also the host adaptation strategies are the key to developing sustainable management practices [3].

Downy mildew disease is one of the most devastating diseases of grapes in viticulture areas with frequent rains, high humidity, and mild temperature in the summer period $[4,5]$. It is a common grapevine disease that has drawn much attention because of the severe economic losses it causes. The grape downy mildew pathogen $P$. viticola causes infection on the leaves, stem, and young berries. The pathogen forms oil spot lesions on the adaxial leaf surface along with severe sporulation on the abaxial leaf surface.

$P$. viticola, being an obligate oomycete biotroph, completes its whole life cycle on the host grapevine. Earlier, P. viticola was endemic only to North America, but in the 1870s it was accidentally introduced to Europe and caused epidemics on $V$. vinifera cultures all over Europe in the subsequent decades [5]. Downy mildew disease can be usually managed by chemical fungicide applications, such asmetalaxyl or Phosethyl-Al, neutralized Bordeaux mixture, and copper oxy-chloridemancozeb. However, indiscriminate use of fungicides not only leads to the emergence of resistant pathogens [6] but the impacts of pesticide overuse exert dangerous effects on human health and cause environmental pollution [7]. This concern has generated interest into the search for eco-friendly substitutes. Hence, research in the area of resistance mechanisms in grapes and development of sustainable management strategies for $P$. viticola infections is the current need.

In recent times, microRNAs (miRNAs) are found to exhibit important roles in controlling the devastating pathogen-causing disease in plants [8,9]. MicroRNAs (miRNAs) are endogenous $\approx 21 \mathrm{nt}$ non-coding RNAs derived from single-stranded RNA precursors, and they form stem-loop structures $[10,11]$. MicroRNAs were first identified in Caenorhabditis elegans and eventually were observed in most of all eukaryotes [12]. miRNAs play a crucial role in higher plants in different developmental stages by regulating gene silencing at transcriptional and post-transcriptional levels [13-15]. Conventional methods do not generally provide information about these miRNAs. The next-generation sequencing (NGS) technology developed recently has been widely applied for genomic investigations such as genome sequencing and gene expression pattern analysis, along with small RNA sequencing. The advantage of ultra-high-throughput through this technology is that many new miRNAs with low abundance can be identified. NGS technologies generate an enormous amount of short sequence data, creating technical issues for bioinformaticists and computational biologists, as well as in analyzing NGS data in meaningful ways [16].

Plant miRNAs have significant roles in plant biotic stress responses. Plant miRNA genes are transcribed by RNA polymerase enzyme, which gives rise to miRNA (primiRNA). The pri-miRNA forms an unfit fold-back structure, further processed into a stem-loop precursor (pre-miRNA) by nuclear RNase-like enzymes known as DICER-LIKE proteins [17]. A mature miRNA sequence is made up of 19 to 24 nucleotides (nt) in length and is responsible for acting as a significant molecule in post-transcriptional gene silencing by base-pairing with target mRNAs. This leads to target mRNA fracture or translational repression, dependent on the degree of complementarily amongst the miRNA and its target transcript [10]. The same mature miRNA can be also present as several variants of their sequence in length. These members of miRNA variants are depicted as iso-miRNAs, the forms of microRNAs. During pre-miRNA processing, the iso-miRNAs are generated by alternative or indistinct cleavage of DICER [18]. Iso-miRNAs have been observed in both plants and animals [19]. 
A high-throughput degradome library sequencing technology has been developed for the global identification of targets of miRNAs in Arabidopsis, grapevine, and rice [20-22]. Many plant processes have recorded functions of plant miRNAs, which also includes developmental transitions [14,23], leaf growth [24], organ polarity [25], auxin signaling [26], and RNA metabolism [27-29]. Plants have evolved multiple orchestrated adaptive response mechanisms to re-program gene expression at the transcriptional, post-transcriptional, and post-translational levels to cope with biotic and abiotic stresses [30], and there are reports suggesting that there is increasing evidence indicated that miRNAs play important roles in plants in response to abiotic and biotic stresses [31].

For the determination of the transcriptional responses to downy mildew infection, profiling of transcripts has been successfully employed. Plant miRNAs were first described in Arabidopsis thaliana and were reported in other species eventually. The observation from different instances has emphasized that that these miRNAs play an important role in biotic and abiotic stress tolerance [30]. For example, in Arabidopsis, miR393 and other miRNAs are produced upon cold stress [29,32], and in rice plants, miR169g and miR393 are upregulated due to drought stress [33]. Under normal conditions, Arabidopsis miR398 directs the cleavage of CSD1 and CSD2 mRNA, bringing about downregulation of miR398 by inducing oxidative stress, which results in the production of CDS1 and CSD2 mRNAs [34]. Some investigations in Arabidopsis have shown that miR399, miR395, and miR398 are induced in response to phosphate-, sulfate-, and $\mathrm{Cu}^{2+}$-deprived conditions, respectively [15,31,35-37]. Moreover, among the 42 Populus miRNA families, the expression of some miRNAs is changed in response to abiotic stress conditions such ascold, heat, salinity, and dehydration, along with other mechanical stresses [38].

The miR393-guided post-transcriptional regulation plays an important role in the plant defense against pathogens targeting an auxin receptor, the transport inhibitor response 1 (TIR1) [39]. In an independent study, Goyal et al. [40] determined the role of miRNAs in defense signaling pathways by the involvement of NBS-LRR gene expression, production of reactive oxygen species (ROS), and hormone signals, which contribute to breed pathogen resistance plants. Transgenic Arabidopsis overexpressing miR393a exhibit increased tolerance to the pathogen P. syringae pv. tomato [30]. Another study from loblolly pine has also shown the expression of 10 miRNAs to be decreased in response to the rust fungus [41].

To detect new miRNAs participating in finding a way to create resistance against the downy mildew disease (DM)-causing pathogen, we constructed cDNA libraries to identify miRNAs involved in grapevine downy mildew resistance and validatedthe miRNA by qRT-PCR. To the best of our knowledge, this study is the first report to usehigh-throughput sequencing technology to investigate molecular events underlying induced disease resistance in grapes for downy mildew disease.

\section{Materials and Methods}

\subsection{Plant Materials and Treatments}

One-year-old grapevine plant cultivar Thompson was grown under field conditions. The pathogen, Plasmopara viticola, which was previously isolated from grapevine downy mildew-infected plants from Vijayapur, Karnataka, India, was used [4]. Young leaves from healthy plants were inoculated with the downy mildew pathogen Plasmopara viticola. Downy mildew-infected leaves selected from the crop field were collected in the evening hours, the harvested leaves were incubated overnight in moist conditions, sporangiareleasing zoospores were collected in the early morning using sterile distilled water (SDW), and the loads were adjusted to $5 \times 10^{-4}$ zoospores $\mathrm{mL}^{-1}$ using a hemocytometer. Later, 10 randomly selected healthy grapevine plants were sprayed with grapevine downy mildew pathogen $P$. viticola suspension of $5 \times 10^{-4}$ zoospores $\mathrm{mL}^{-1}$ (served as pathogen-infected plants); another set of 10 plants were smeared or sprayed with the biopesticide Trichoderma harzianum (TriH_JSB36) at $1 \times 10^{-8}$ spores $\mathrm{mL}^{-1}$ untilrun-off (served as TriH_JSB-36-treated plants); and lastly, 10 plants were sprayed with sterile distilled water 
(served as SDW control plants) [42]. These three sets of treated plants (pathogen-infected, TriH_JSB36-treated, and SDW-control plants) were maintained in similar conditions. Sample leaves from the treated and control plants were collected in liquid nitrogen at $24 \mathrm{~h}$ after inoculation and were stored at $-80{ }^{\circ} \mathrm{C}$ for further experiments [43].

\subsection{Total RNA Isolation and Quality Assessment}

Total RNA isolation was carried out from a frozen $(24 \mathrm{~h})$ three set of samples using the MagMAX Plant RNA Isolation Kit (Thermo Fisher Scientific, Waltham, MA, USA). Total RNA was isolated using the manufacturer's protocol. The quality and quantity of total RNA was determined using Bioanalyzer and Qubit Fluorometer. Bioanalyzer uses a lab on a chip approach to perform capillary electrophoresis to analyze RNA. The technique is based on the use of a fluorescent dye that binds to RNA to determine RNA integrity. The fluorescent dye molecules intercalate into RNA strands. They are then detected by their fluorescence and translated into gel-like images (bands) and electropherograms (peaks). The integrity of RNA is determined by RNA integrity number (RIN) depending on the peaks. RIN values are measured from 1 to 10 , where RIN value $1-5$ indicates complete degradation, 5-7 indicates partially degraded RNA, and RIN values above 8 indicate good quality RNA.

The Qubit Fluorometer is a unique fluorometer designed to work seamlessly with highly specific and sensitive Qubit RNA quantification assays. The Quant-iT ${ }^{\mathrm{TM}}$ RiboGreen RNA Assay Kit contains Quant-iT ${ }^{\mathrm{TM}}$ RiboGreen RNA reagent along with buffers and RNA standards. Quant-i ${ }^{\mathrm{TM}}$ RiboGreen RNA reagent is used as a very sensitive detection dye for the quantification of RNA in solution, with linear fluorescence detection in the range of 2-200 ng of RNA.

\subsection{Small RNA Sequencing}

Isolated RNA from treated and non-treated samples were used for small RNA highthroughput sequencing (HTS), and the sequence data were generated using Illumina HiSeq sequencing technology at the Clevergene Biocorp Pvt. Ltd., Bengaluru, India. The quality of the data was checked using FastQC [44] and MultiQC [45] software. The adapter sequences, low-quality bases, and the reads shorter than $17 \mathrm{bp}$ were removed using the Trim Galore [46] tool.

\subsection{Alignment and Identification of miRNA}

The QC passed reads were mapped onto the indexed grapevine reference genome (GCF_000003745.3_12X); vine grape using the mapper.pl script of miRDeep2 [47]. Reads mapped to the reference genome were used to identify miRNAs with miRDeep2 using known and novel miRNA detection parameters. V. vinifera and A. thaliana (as related species) mature miRNAs from mirBase v22.1 [48] were used for miRNA prediction. A total of 389 novel and 76 known miRNAs were identified; miRNAs with miRDeep score less than 1 were excluded from further analysis, resulting in 284 novel and 63 known miRNAs. Expression levels of miRNAs were estimated using miRDeep2 quatifiler.pl script. For GO enrichment tests, we used Arabidopsis (TAIR10) peptide annotations, while BlastX program was used to align the unigenes with e-value $\leq 1 \times 10^{-5}$. The top blast hits were deliberated as putative orthologous genes. $V$. vinifera unigenes were annotated with GO for Arabidopsis POGs. The GO was analyzed with BiNGO plugins [49] for Cytoscape using the hypergeometric test for statistical analysis. We used the Bonferroni correction method for e-value corrections to find over-representative terms with BiNGO.

\subsection{Expression of Differential miRNAs}

Differential expression analysis was carried out using the DESeq2 [50] package. The read counts were normalized, and differential expression was tested. MiRNAs with absolute $\log _{2}$ fold change $\geq 1$, and $p$-value $\leq 0.05$ was considered significant. A total of 15 miRNAs were significantly differentially expressed in pathogen-infected samples 
(Test) when compared to SDW-control samples. No significant miRNAs were identified in SDW-control vs. TriH_JSB36-treated and TriH_JSB36-treated vs. pathogen-infected comparisons. The expression profile of the differentially expressed miRNAs across the samples is presented in volcano plots and a heatmap.

\section{Results}

\subsection{Small RNAs from Vitis vinifera}

To identify downy mildew responsive miRNAs in grapevines, we generated total RNAs from young leaves (SDW-control, TriH_JSB36-treated, and pathogen-infected) for high-throughput sequencing, yielding 22,492,910, 25,476,471, and 22,448,438 raw read totals from the SDW-control, TriH_JSB36-treated, and pathogen-infected libraries, respectively (Table 1).

Following filtration, $13,460,335,114,114,82$, and $116,415,018$ clean reads were obtained and mapped onto the $V$. vinifera reference genome, respectively (mature miRNAs from mirBase v22.1 and were used for miRNA prediction). The length distribution analysis of raw and filtered reads showed that the small RNA length from $V$. vinifera varied from 20 to $24 \mathrm{nt}$ in both the SDW-control and the TriH_JSB36- treated and pathogen-infected groups (Figure 1).

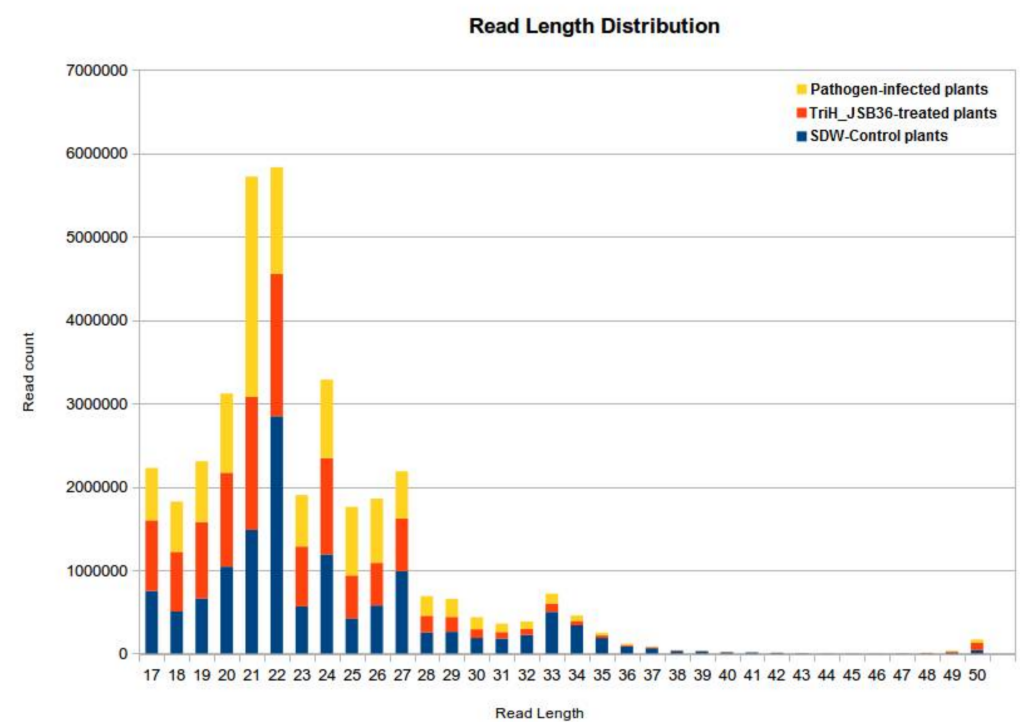

Figure 1. Length distribution analysis of reads for SDW-control, TriH_JSB36-treated, and pathogeninfected (Test) samples used for miRDeep2 analysis.

Table 1. Number of raw reads and read length distribution before and after $Q C$ filtering and trimming of SDW-control, TriH_JSB36-treated, and pathogen-infected (Test) samples used for miRDeep2 analysis obtained by high-throughput sequencing.

\begin{tabular}{ccc}
\hline & Raw Reads & \\
\hline Sample Name & Number of Reads & Read Length \\
\hline SDW-control & $22,492,910$ & 50 \\
TriH_JSB36-treated & $25,476,471$ & 50 \\
Pathogen-infected (Test) & $22,448,438$ & 50 \\
\hline & Reads after QC Filtering and Trimming & \\
\hline Sample Name & Number of Reads & Read Length \\
\hline SDW-control & $13,460,335$ & $17-50$ \\
TriH_JSB36-treated & $11,411,482$ & $17-50$ \\
Pathogen-infected (Test) & $11,641,501$ & $17-50$ \\
\hline
\end{tabular}




\section{2. miRNA Identification from Vitis vinifera}

The processing of filtered reads from high-throughput sequencing was carried out according to miRDeep-P workflow, and the expression levels of miRNAs were estimated using miRDeep2 quatifiler.pl script with the $V$. vinifera genome as the reference sequence. For the SDW-control samples, a total of 347 miRNAs were identified, out of which $300 \mathrm{miRNAs}$ were expressed, resulting in 63 known and 237 novel miRNAs. In the TriH_JSB36-treated sample, 321 expressed miRNAs including 63 known and 258 novel miRNAs were identified, and in the infected RNA samples, out of 304 expressed miRNAs, 63 known and 241 novel miRNAs were identified (Table 2).

Table 2. Identification of total novel and known miRNAs obtained from SDW-control, TriH_JSB36treated, and pathogen-infected (Test) samples with miRDeep score.

\begin{tabular}{ccccc}
\hline Sample Name & Total miRNAs & $\begin{array}{c}\text { Expressed } \\
\text { miRNAs }\end{array}$ & $\begin{array}{c}\text { Known } \\
\text { miRNAs }\end{array}$ & $\begin{array}{c}\text { Novel } \\
\text { miRNAs }\end{array}$ \\
\hline SDW-control & 347 & 300 & 63 & 237 \\
\hline TriH_JSB36-treated & 347 & 321 & 63 & 258 \\
\hline Pathogen-infected (Test) & 347 & 304 & 63 & 241 \\
\hline
\end{tabular}

On the basis of the sequencing results and analysis (differential expression analysis), we found significant differences in the expression study observed in 15 miRNAs expressed (five upregulated, and 10 downregulated) in the pathogen-infected sample (Test) in comparison to the SDW-control sample. The largest families obtained were vvi-miR395 family (vvi-miR395k, vvi-miR395i, vvi-miR395e, vvi-miR395d, vvi-miR395e, vvi-miR395e, vvimiR395j, vvi-miR395a, vvi-miR395c and vvi-miR395l) with average $-4.66 \log _{2}$ fold change (downregulated). No significant miRNAs were identified in SDW-control vs. TriH_JSB36treated and TriH_JSB36-treated vs. pathogen-infected comparisons (Table 3). Volcano plot and heatmap represented the expression profile of the differentially expressed miRNAs across the samples (Figures 2 and 3, respectively).

Table 3. Number of differentially expressed (i.e., upregulated and downregulated) miRNAs obtained from SDW-control vs. pathogen-infected, SDW-control vs. TriH_JSB36-treated, and TriH_JSB36treated vs. pathogen-infected (Test) samples.

\begin{tabular}{cccc}
\hline Condition (Control vs. Test) & $\begin{array}{c}\text { Significantly } \\
\text { Expressed } \\
\text { miRNAs }\end{array}$ & $\begin{array}{c}\text { Upregulated } \\
\text { miRNAs }\end{array}$ & $\begin{array}{c}\text { Downregulated } \\
\text { miRNAs }\end{array}$ \\
\hline SDW-control vs. pathogen-infected & 15 & 5 & 10 \\
SDW-control vs. TriH_JSB36-treated & 0 & 0 & 0 \\
TriH_JSB36-treated vs. \\
pathogen-infected
\end{tabular}



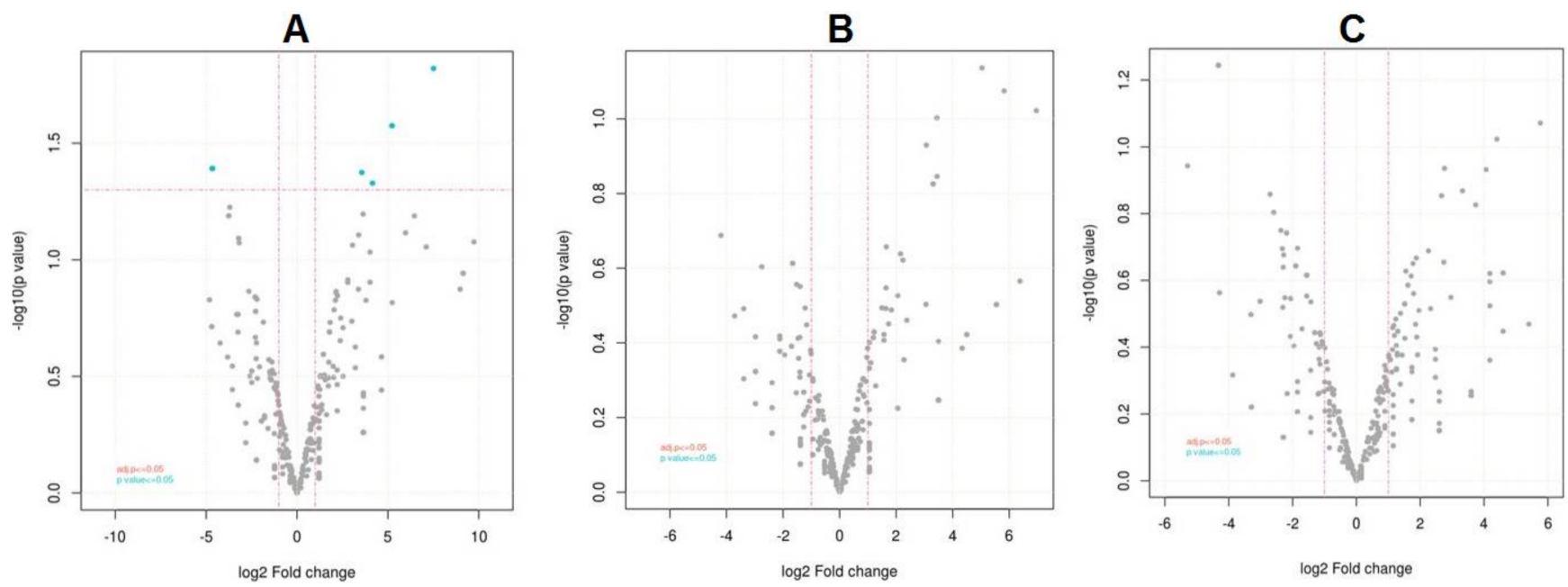

Figure 2. Volcano plot showing differential expression level of miRNAs. (A) Volcano plot for SDW-control vs. pathogeninfected plants, (B) SDW-control vs. TriH_JSB36-treated plants, (C) TriH_JSB36-treated vs. pathogen-infected plants.

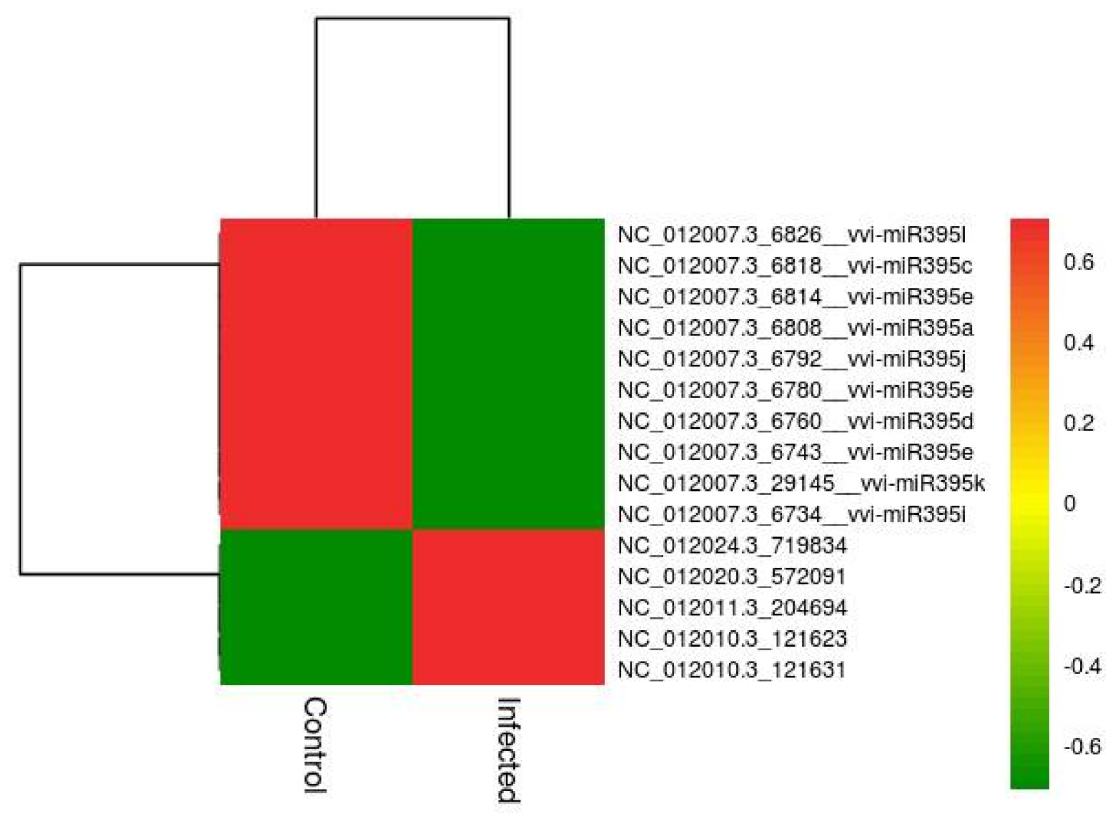

Figure 3. Heatmap of expression profile ( $\log _{2}$-based values) (upregulation vs. downregulation) of the differential expressed miRNAs in SDW-control vs. pathogen-infected samples. The heatmap was generated using the Rstudio program (A package of R, USA).

\subsection{Target Prediction of voi-miRNAs}

Targets for all significant novel and known miRNAs were obtained using miRanda [51], an algorithm for the detection of potential microRNA target sites in genomic sequences. The predicted targets were filtered on the basis of their pairing score $(>150)$ and pairing energy score $(<-20 \mathrm{Kcal} / \mathrm{Mol})$. The identification and characterization of targets are essential to elucidate the functions of the miRNAs.

Finally, a total of 1061 known and 103 novel experimentally verified or putative transcripts were predicted for $347 \mathrm{vvi-miRNAs.} \mathrm{The} \mathrm{analysis} \mathrm{showed} \mathrm{that} \mathrm{the} \mathrm{many}$ targets of conserved miRNA were transcription factors. Gene Ontology and pathways were enriched for target genes using DAVID [52]. Significantly enriched gene ontology terms and KEGG pathways are presented in Figure 4 for 'regulation of biological process', 
'signal transduction', and 'cellular response to stress', which are the most enriched terms of biological process.

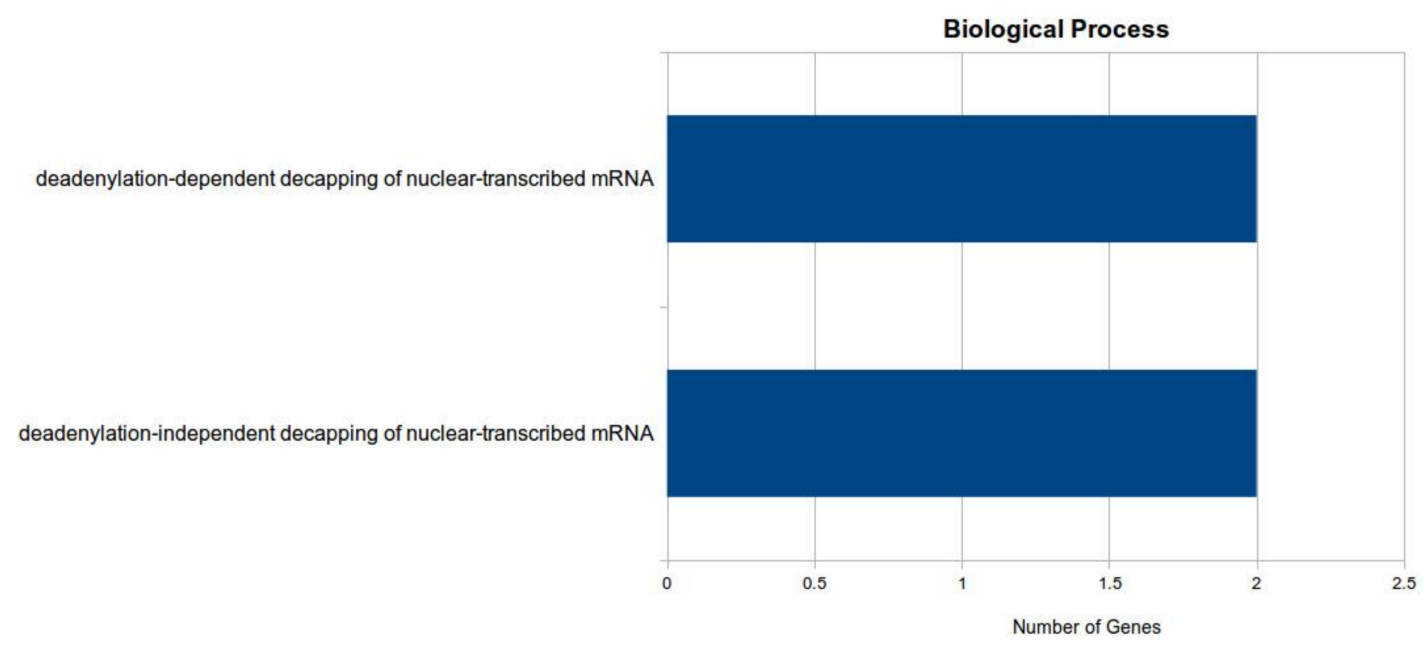

Figure 4. Gene Ontology annotation for all the predicted targets of miRNA genes involved in deadenylation-dependent and independent decapping of nuclear transcribed mRNA.

All the putative targets were analyzed for Gene Ontology (GO) and pathway analysis. In GO-categorized miRNAs, the three main GO terms were cellular component, KEGG for various miRNA involved, and molecular function. The significantly enriched terms of cellular component (Figure 5) included 'regulation of cytoplasmic mRNA processing body assembly', 'nucleus', and 'intracellular membrane-bounded organelle'.

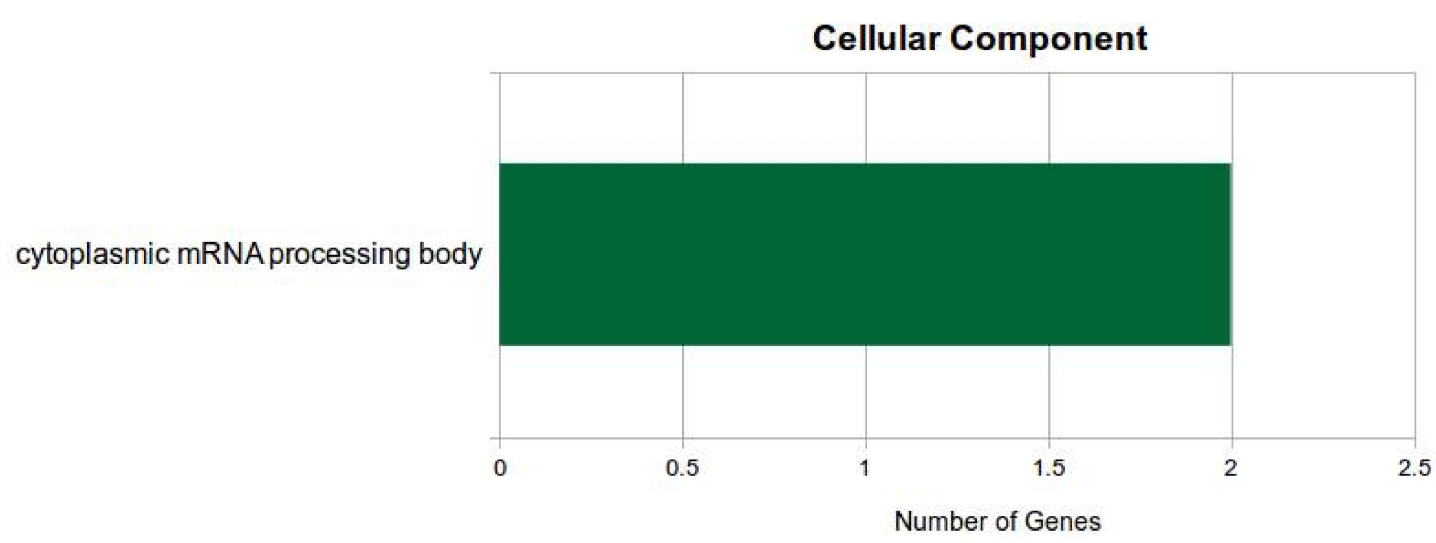

Figure 5. Number of differentially expressed miRNA genes in cytoplasmic mRNA processing body.

Similarly, for miRNA involved in various pathways (Figure 6), the terms were spliceosome, phosphatidyl inositol signaling system, inositol phosphate metabolism, and RNA degradation. 


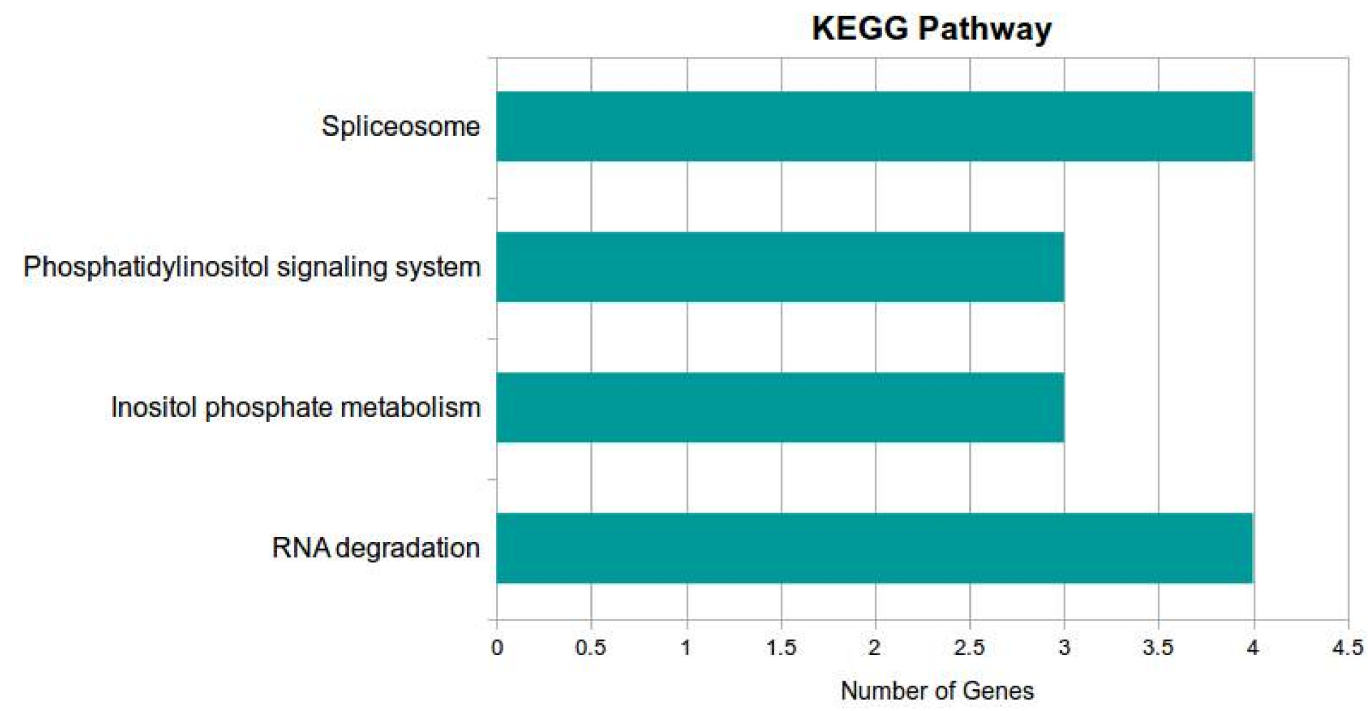

Figure 6. miRNAs involved in various pathways, namely, spliceosome, phosphatidyl inositol signaling system, inositol phosphate metabolism, and RNA degradation.

In the molecular function (Figure 7), 'DNA polymerase activity' and 'ATP-dependent $\mathrm{NAD}(\mathrm{P}) \mathrm{H}-\mathrm{hydrate}$ dehydratase activity' in catalytic activity, and 'RNA binding' and 'protein complex' were found to be significantly enriched terms $(p<0.05)$.

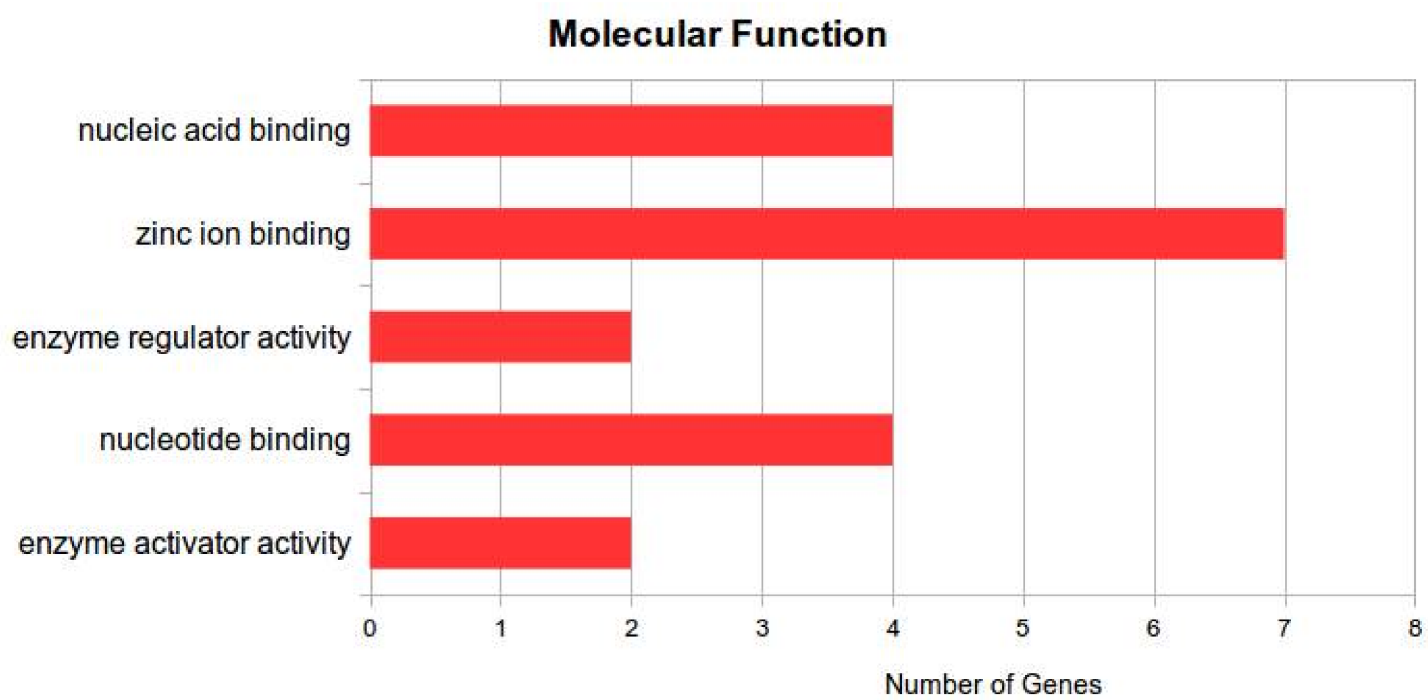

Figure 7. Genes involved in nucleic acid binding, zinc ion binding, enzyme regulator activity, nucleotide binding, and enzyme activator activity.

A total of 79 novel and 91 known miRNAs were identified on the basis of the previous studies on $\mathrm{R}$ genes along with GO terms. For novel miRNAs, 11 significant $\mathrm{GO}$ categories were enriched, and 9 of them belonged to cellular components. GO: 0044428 (nuclear part) was the most significant, reaching $5.39 \times 10^{-4}$, indicating that most of the genes were located in the nucleus, and 9 genes were further enriched in the nucleoplasm. In addition, 20 genes were enriched for GO: 0032991 (macroscopic complex). The other two significant categories belonged to biological processes, which are involved in mRNA metabolic and DNA packaging, respectively. For known miRNAs, there may be too few genes, and thus we did not find a significant category (FDR $<0.05$ ). Therefore, we enlarged the scope of screening and selected the GO category with FDR $<0.08$. A total of 21 genes are responsible in the regulating various biological processes, including seven genes involved in signal 
transduction (GO: 0050789), rhythm regulation, and stress response. In the molecular function category, 10 and 2 genes were enriched into RNA binding and DNA-directed DNA polymerase activity, respectively.

\section{4. qRT-PCR Validation of miRNAs}

To validate the accuracy and consistency of the micro-RNA-seq findings, we randomly selected 12 MIR genes to quantify the expression patterns using qRT-PCR analysis in SDW-control, TriH_JSB36-treated, and pathogen-infected grapevine leaf samples (Figure 8). In qRT-PCR analysis, four MIR genes showed higher activity in SDW-control plants, while they were slightly decreased in infected plants and significantly enhanced in the TriH_JSB36-treated plants. Three genes depicted normal expression in SDW-control but were moderately enhanced in pathogen-infected and TriH_JSB36-treated plants. However, the remaining five MIR genes showed enhanced activity at a very low level in treated grapevine leaf samples. Overall, the qRT-CPR findings were consistent with highthroughput sequencing data, reflecting the accuracy of the experimental findings.

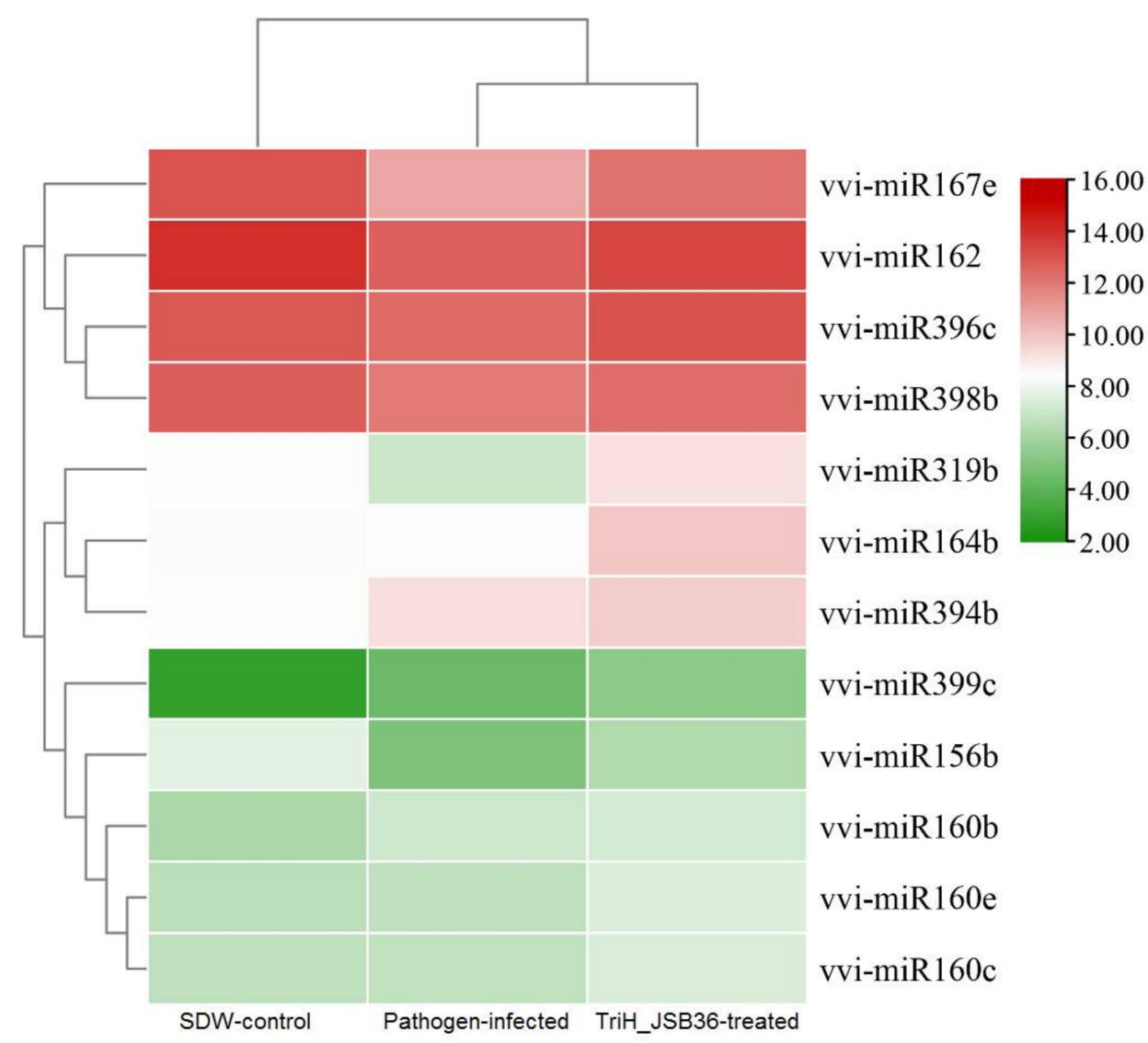

Figure 8. Expression of target mRNA transcript by qRT-PCR in response to SDW-control, pathogen-infected, and TriH_JSB36treated plants. The heatmap was developed using $\log _{2}$ value from the Rstudio program (A package of R, USA).

\section{Discussion}

The complex miRNA-mediated regulatory networks controlling various physiological processes requires in depth studies that will lay the path to unravel identifying the entire set of miRNAs and their targets. Several genetic studies have reported that organisms may contain about $1 \%$ miRNA genes of the total protein-coding genes [53-55]. These miRNAs are widely present in animals and plants as the key regulators of these gene expressions [56-58]. There are 243 and 511 miRNAs annotated in Arabidopsis and rice, respectively, according to the miRBase database $[59,60]$. For resistance breeding in the commercially cultivated $V$. vinifera to be enhanced, the identification of major gene 
regulators during downy mildew susceptibility and resistance is crucial. In the present study, total RNAs from young leaves (sterile distilled water (SDW)-control, biopesticide, TriH_JSB36-treated, and pathogen-infected) were extracted for high-throughput sequencing, yielding 22,492,910, 25,476,471, and 22,448,438 raw read totals from the SDW-control, TriH_JSB36-treated, and pathogen-infected libraries, respectively. The primary goal of this study was the identification of $P$. viticola pathogenicity factors involved in the infection process of grapevine. To enable the use of transcriptomic approaches, we first sequenced the RNA isolated from the infected plants followed by assembling the P. viticola genome.

For the screening of miRNA, the most widely used method is small RNA highthroughput sequencing, encouraging the detection of an enormous number of sRNA in different plant species. Hence, the present study also took up this method to identify miRNAs in $V$. vinifera. In most of the research studies, the common lengths of plant sRNA are usually 21 or $24 \mathrm{nt}[56,61,62]$. According to reports, in some plants, the number of $24 \mathrm{ntsRNA}$ usually exceeds $21 \mathrm{nt}$ sRNA, for example, in gymnosperms Taxus chinensis [63];in monocots Oryza sativa [64]; and in eudicots Arabidopsis [56], tomato [62], and Citrus trifoliate [16]. Similarly in the present study, the length distribution analysis for row and filtered reads showed that the small RNA length from $V$. vinifera varied from 20 to $24 \mathrm{nt}$ in both the SDW-control and the TriH_JSB36 and pathogen-treated groups.

In this study, the sequence data were generated using Illumina HiSeq sequencing technology, and a total of 347 miRNAs for SDW-control samples were identified, out of which 300 miRNAs were expressed, resulting in 63 known and 237 novel miRNAs. In the TriH_JSB36-treated sample, 321 expressed miRNAs including 63 known and 258 novel miRNAs were identified, and in infected RNA samples, out of 304 expressed miRNAs, 63 known and 241 novel miRNAs were identified. Similar supporting data were documented by Yang et al. [65], wherein the authors identified the role of isolated miR482 involved in modulating resistance against Verticillium dahlia in potato, with the resistance being correlated with the suppression of NBS-LRR genes. The same trend in disease resistance to Fusarium oxysporum was observed in tomato with miR482 [66].

The relative expression between TriH_JSB36-treated vs. SDW-control plant miRNAs and the respective target genes in the trans-regulating state was higher than in the cisregulating state. Nevertheless, the expression profiles of some miRNAs were negatively related to their target genes (Figure 3). Here, in this study, we found that the significant expression of the 15 miRNAs, of which 5 miRNAs were upregulated in control conditions. Our results are in agreement with rice miRNA (miR7695) that upregulated resistance against M. oryzae [67].

Further, we studied the target genes for the entire significant novel and known miRNAs that were obtained using miRanda. For the plant miRNA identification, MiRDeep-P is an efficient and efficacious tool. In this study, small RNA (sRNA) high-throughput sequencing and data analysis by MiRDeep-P not only has detected known vvi-miRNAs, but also has predicted 258 novel miRNAs from the grapevine leaves treated with fungicides. Previous studies also have reported several novel miRNAs from the $V$. vinifera grapevine cultivars $[68,69]$. Wang et al. reported novel miRNAs from the grapevine cultivar Summer Black [70]. In another study, an increased innate immune response of potato to Phytophthora infestans was observed by auxin response target genes [71]. Although, these novel miRNAs were reported in the above studies, they were not found in this study. The reason could be the experimental conditions used for library preparations and as well as the geographical and environmental factors of the cultivars.

A fascinating finding from the present study is that the number of target genes that have been selected for miRNA expression is very large. On the basis of the previous studies, we found that most of the expressed miRNAs (conserved) and their targets are transcription factors. miRNAs play a crucial role in plants by regulating growth and development and are responsible for survival [72]. However, the function of conserved miRNAs is not always conserved [73], e.g., for each of the three conserved miRNA families, miR478a, miR473a, and miR482, the miRNA families from rice and Populus have assorted 
functions. The conserved miRNAs families are primarily involved in stress responses, although the non-conserved miRNAs targets are significantly varied, unfolding the diverse roles of miRNAs in different biological systems.

\section{Conclusions}

This study explores the molecular defense mechanisms of grapes to downy mildew.At the level of post-transcription regulation, we identified miRNAs from a highly resistant grapevine cultivar. Combined with sRNA high-throughput sequencing, bioinformatics, and molecular biology technologies, the identified vvi-miRNAs further need to be investigated for their role in downy mildew resistance to $V$. vinifera. Moreover, in-depth studies on these miRNAs and their target genes will further expand our understanding of the molecular mechanisms underlying downy mildew resistance in $V$. vinifera, paving a way to detect the possible involvement of NBS-LRR gene expression in defense signals as in other cases.

Author Contributions: Conceptualization, project administration, supervision, and funding acquisition S.J.; methodology, M.V.K.; software, M.V.K., N.G., A.B.S., B.A. and S.J.; validation, M.V.K., S.A., N.G., A.B.S. and S.J.; formal analysis, M.V.K., A.B.S., S.A., A.S., B.A. and S.J.; investigation, data curation and resources, M.V.K. and S.J.; writing—original draft preparation, M.V.K., N.G., A.B.S., S.A., N.G., A.S., B.A. and S.J. All authors have read and agreed to the published version of the manuscript.

Funding: This research received no external funding.

Acknowledgments: All the authors are grateful to the facilities available at Laboratory of Plant Healthcare and Diagnostics, PG Department of Biotechnology and Microbiology, Karnatak University, Dharwad, for providing research grants to S.J. The authors also extend their appreciation to the Researchers Supporting Project number (RSP-2021/367), King Saud University, Riyadh, Saudi Arabia.

Conflicts of Interest: The authors do not have any competing interests regarding this submitted work.

\section{References}

1. International Organization of Vine and Wine. 2019 Statistical Report on World Vitiviniculture. Available online: https://www.oiv. int/public/medias/6782/oiv-2019-statistical-report-on-world-vitiviniculture.pdf (accessed on 22 September 2021).

2. Thines, M.; Kamoun, S. Oomycete-plant coevolution: Recent advances and future prospects. Curr. Opin. Plant Biol. 2010, 13, 427-433. [CrossRef] [PubMed]

3. Dussert, Y.; Mazet, I.D.; Couture, C.; Gouzy, J.; Piron, M.C.; Kuchly, C.; Bouchez, O.; Rispe, C.; Mestre, P.; Delmotte, F.A. High-Quality Grapevine Downy Mildew Genome Assembly Reveals Rapidly Evolving and Lineage-Specific Putative Host Adaptation Genes. Genome Biol. Evol. 2019, 11, 954-969. [CrossRef] [PubMed]

4. Milan, V.K.; Joshi, S.M.; Hadimani, S.; Jogaiah, S. Biopriming with rhizosphere Trichoderma harzianum elicit protection against grapevine downy mildew disease by triggering histopathological and biochemical defense responses. Rhizosphere 2021, 19, 100398. [CrossRef]

5. Gessler, C.; Pertot, I.; Perazzolli, M. Plasmopara viticola: A review of knowledge on downy mildew of grapevine and effective disease management. Phytopathol. Mediterr. 2011, 50, 3-44.

6. Chen, W.J.; Delmotte, F.; Richard-Cervera, S.; Douence, L.; Greif, C.; Corio-Costet, M.F. At least two origins of fungicide resistance in grapevine downy mildew populations. Appl. Environ. Microbiol. 2007, 73, 5162-5172. [CrossRef]

7. Pimentel, D.; Acquay, H.; Biltonen, M.; Rice, P.; Silva, M.; Nelson, J.; Lipner, V.; Giordano, S.; Horowitz, A.; D’Amore, M. Environmental and economic costs of pesticide use. Bioscience 1992, 42, 750-760. [CrossRef]

8. Djami-Tchatchou, A.T.; Sanan-Mishra, N.; Ntushelo, K.; Dubery, I.A. Functional Roles of microRNAs in Agronomically Important Plants-Potential as Targets for Crop Improvement and Protection. Front. Plant Sci. 2017, 8, 378. [CrossRef]

9. Yang, X.; Zhang, L.; Yang, Y.; Schmid, M.; Wang, Y. miRNA Mediated Regulation and Interaction between Plants and Pathogens. Int. J. Mol. Sci. 2021, 22, 2913. [CrossRef]

10. Bartel, D.P. MicroRNAs: Genomics, biogenesis, mechanism, and function. Cell 2004, 116, 281-297. [CrossRef]

11. Chen, X.M. Small RNAs and their roles in plant development. Annu. Rev. Cell Dev. Biol. 2009, 25, 21-44. [CrossRef]

12. Fire, A.; Xu, S.; Montgomery, M.K.; Kostas, S.A.; Driver, S.E.; Mello, C.C. Potent and specific genetic interference by doublestranded RNA in Caenorhabditis elegans. Nature 1998, 391, 806-811. [CrossRef]

13. Llave, C.; Xie, Z.; Kasschau, K.D.; Carrington, J.C. Cleavage of Scarecrow-like mRNA targets directed by a class of Arabidopsis miRNA. Science 2002, 297, 2053-2056. [CrossRef]

14. Aukerman, M.J.; Sakai, H. Regulation of flowering time and floral organ identity by a MicroRNA and its APETALA2-like target genes. Plant Cell 2003, 15, 2730-2741. [CrossRef] 
15. Bari, R.; Datt, P.B.; Stitt, M.; Scheible, W.R. PHO2, microRNA399, and PHR1 define a phosphate-signaling pathway in plants. Plant Physiol. 2006, 141, 988-999. [CrossRef]

16. Song, C.; Wang, C.; Zhang, C.; Korir, N.K.; Yu, H.; Ma, Z. Deep sequencing discovery of novel and conserved microRNAs in trifoliate orange (Citrus trifoliata). BMC Genom. 2010, 11, 431. [CrossRef]

17. Vainnet, O. Origin, biogenesis, and activity of plant microRNAs. Cell 2009, 136, 669-687. [CrossRef]

18. Guo, L.; Lu, Z. Global expression analysis of microRNA gene cluster and family based on isomiRs from deep sequencing data. Comput. Bio. Chem. 2010, 34, 165-171. [CrossRef]

19. Naya, L.; Khan, G.A.; Sarin, C.; Hartman, C.; Cerspi, M.; Lelandais-Briere, C. Clevage of non-conserved target by a specific miR156 isoform in root apexes of Medicago truncatulla. Plant Signal. Behav. 2010, 5, 328-331. [CrossRef]

20. Addo-Quaye, C.; Miller, W.; Axtell, M.J. A pipeline for using degradome data to find cleaved small RNA targets. Bioinformatics 2009, 25, 130-131. [CrossRef]

21. Li, Y.F.; Zheng, Y.; Addo-Quaye, C.; Zhang, L.; Saini, A.; Jagadeeswaran, G.; Axtell, M.J.; Zhang, W.X.; Sunkar, R. Transcriptomewide identification of microRNA targets in rice. Plant J. 2010, 62, 742-759. [CrossRef]

22. Wu, L.; Zhang, Q.Q.; Zhou, H.Y.; Ni, F.R.; Wu, X.Y.; Qi, Y.J. Rice microRNA effector complexes and targets. Plant Cell 2009, 21, 3421-3435. [CrossRef]

23. Chen, C.Z.; Li, L.; Lodish, H.F.; Bartel, D.P. MicroRNAs modulate hematopoietic lineage differentiation. Science 2004, 303, 83-86. [CrossRef]

24. Palatnik, J.F.; Allen, E.; Wu, X.; Schommer, C.; Schwab, R.; Carrington, J.C.; Weigel, D. Control of leaf morphogenesis by microRNAs. Nature 2003, 425, 257-263. [CrossRef]

25. Kidner, C.A.; Martienssen, R.A. Spatially restricted microRNA directs leaf polarity through ARGONAUTE1. Nature 2004, 428, 81-84. [CrossRef]

26. Jones-Rhoades, M.W.; Bartel, D.P. Computational identification of plant microRNAs and their targets, including a stress-induced miRNA. Mol. Cell 2004, 14, 787-799. [CrossRef]

27. Vaucheret, H.; Vazquez, F.; Crete, P.; Bartel, D.P. The action of ARGONAUTE1 in the miRNA pathway and its regulation by the miRNA pathway are crucial for plant development. Genes Dev. 2004, 18, 1187-1197. [CrossRef]

28. Xie, Z.; Kasschau, K.D.; Carrington, J.C. Negative feedback regulation of Dicer-Like1 in Arabidopsis by microRNA-guided mRNA degradation. Curr. Biol. 2003, 13, 784-789. [CrossRef]

29. Zhou, X.; Wang, G.; Sutoh, K.; Zhu, J.K.; Zhang, W. Identification of cold inducible microRNAs in plants by transcriptome analysis. Biochim.Biophys. Acta 2008, 1779, 780-788. [CrossRef]

30. Shukla, L.I.; Chinnusamy, V.; Sunkar, R. The role of microRNAs and other endogenous small RNAs in plant stress responses. Biochim. Biophys. Acta 2008, 1779, 743-748. [CrossRef]

31. Sunkar, R.; Chinnusamy, V.; Zhu, J.; Zhu, J.K. Small RNAs as big players in plant abiotic stress responses and nutrient deprivation. Trends Plant Sci. 2007, 12, 301-309. [CrossRef]

32. Sunkar, R.; Zhu, J.K. Novel and stress-regulated microRNAs and other small RNAs from Arabidopsis. Plant Cell 2004, 16, 2001-2019. [CrossRef] [PubMed]

33. Zhao, Y.; Srivastava, D. A developmental view of microRNA function. Trends Biochem. Sci. 2007, 32, 189-197. [CrossRef] [PubMed]

34. Sunkar, R.; Kapoor, A.; Zhu, J.K. Posttranscriptional induction of two Cu/Zn superoxide dismutase genes in Arabidopsis is mediated by downregulation of miR398 and important for oxidative stress tolerance. Plant Cell 2006, 18, 2051-2065. [CrossRef] [PubMed]

35. Fujii, H.; Chiou, T.J.; Lin, S.I.; Aung, K.; Zhu, J.K. A miRNA involved in phosphate starvation response in Arabidopsis. Curr. Biol. 2005, 15, 2038-2043. [CrossRef]

36. Aung, K.; Lin, S.I.; Wu, C.C.; Huang, Y.T.; Su, C.L.; Chiou, T.J. pho2, a phosphate over accumulator, is caused by a nonsense mutation in a microRNA399 target gene. Plant Physiol. 2006, 141, 1000-1011. [CrossRef]

37. Chiou, T.J.; Aung, K.; Lin, S.I.; Wu, C.C.; Chiang, S.F.; Su, C.L. Regulation of phosphate homeostasis by MicroRNA in Arabidopsis. Plant Cell 2006, 18, 412-421. [CrossRef]

38. Lu, Y.D.; Gan, Q.H.; Chi, X.Y.; Qin, S. Roles of microRNA in plant defense and virus offense interaction. Plant Cell Rep. 2008, 27, 1571-1579. [CrossRef]

39. Navarro, L.; Dunoyer, P.; Jay, F.; Arnold, B.; Dharmasiri, N.; Estelle, M.; Voinnet, O.; Jones, J.D. A plant miRNA contributes to antibacterial resistance by repressing auxin signaling. Science 2006, 312, 436-439. [CrossRef]

40. Goyal, N.; Bhatia, G.; Sharma, S.; Garewal, N.; Upadhyay, A.; Upadhyay, S.K.; Singh, K. Genome-wide characterization revealed role of NBS-LRR genes during powdery mildew infection in Vitis vinifera. Genomics 2020, 112, 312-322. [CrossRef]

41. Lu, S.; Sun, Y.H.; Amerson, H.; Chiang, V.L. MicroRNAs in loblolly pine (Pinus taeda L.) and their association with fusiform rust gall development. Plant J. 2007, 51, 1077-1098. [CrossRef]

42. Weng, K.; Li, Z.Q.; Liu, R.Q.; Wang, L.; Wang, Y.J.; Xu, Y. Transcriptome of Erysiphe nector-Infected Vitis vinifera pseudo neticulata leaves provides insight into grapevine resistance to powdery mildew. Hortic. Res. 2014, 1, 14049. [CrossRef]

43. Han, L.; Weng, K.; Ma, H.; Xiang, G.; Li, Z.; Wang, Y.; Liu, G.; Xu, Y. Identification and characterization of Erysiphe nectorResponsive MicroRNAs in Chinese wild Vitis pseudoreticulata by high-throughput sequencing. Front. Plant Sci. $2016,7,621$. [CrossRef] 
44. Andrews, S. FastQC A Quality Control Tool for High Throughput Sequence Data. 2010. Available online: http://www. bioinformatics.babraham.ac.uk/projects/fastqc/ (accessed on 29 July 2020).

45. MultiQC: Summarize Analysis Results for Multiple Tools and Samples in a Single Report | Bioinformatics | Oxford Academic. (n.d.). Available online: https:/ / academic.oup.com/bioinformatics/article/32/19/3047/2196507/MultiQC-summarize-analysisresults-for-multiple (accessed on 14 June 2020).

46. Babraham Bioinformatics_Trim Galore! Available online: https://www.bioinformatics.babraham.ac.uk/projects/trim_galore/ (accessed on 3 May 2017).

47. Friedlander, M.R.; Mackowiak, S.D.; Li, N.; Chen, W.; Rajewsky, N. miRDeep2 accurately identifies known and hundreds of novel microRNA genes in seven animal clades. Nucleic Acids Res. 2012, 40, 37-52. [CrossRef]

48. Kozomara, A.; Griffiths-Jones, S. miRBase: Annotating high confidence microRNAs using deep sequencing data. Nucleic Acids Res. 2014, 42, 68-73. [CrossRef]

49. Maere, S.; Heymans, K.; Kuiper, M. BiNGO: A Cytoscape plugin to assess overrepresentation of Gene Ontology categories in biological networks. Bioinformatics 2005, 21, 3448-3449. [CrossRef]

50. Love, M.I.; Huber, W.; Anders, S. Moderated estimation of fold change and dispersion for RNA-seq data with DESeq2. Genome Biol. 2014, 15, 550. [CrossRef]

51. Betel, D.; Wilson, M.; Gabow, A.; Marks, D.S.; Sander, C. The microRNA.org resource: Targets and expression. Nucleic Acids Res. 2008, 36 (Suppl. 1), D149-D153. [CrossRef]

52. Dennis, G.; Sherman, B.T.; Hosack, D.A.; Yang, J.; Gao, W.; Lane, H.C. DAVID: Database for Annotation, Visualization, and Integrated Discovery. Genome Biol. 2003, 4, 3. [CrossRef]

53. Lim, L.P.; Glasner, M.E.; Yekta, S.; Burge, C.B.; Bartel, D.P. Vertebrate microRNA genes. Science 2003, 299, 1540. [CrossRef]

54. Lim, L.P.; Lau, N.C.; Weinstein, E.G.; Abdelhakim, A.; Yekta, S.; Rhoades, M.W.; Burge, C.B. The microRNAs of Caenorhabditis elegans. Genes Dev. 2003, 17, 991-1008. [CrossRef]

55. Lai, E.C.; Tomancak, P.; Williams, R.W.; Rubin, G.M. Computational identification of Drosophila microRNA genes. Genome Biol. 2003, 4, R42. [CrossRef]

56. Rajagopalan, R.; Vaucheret, H.; Trejo, J.; Bartel, D.P. A diverse and evolutionarily fluid set of microRNAs in Arabidopsis thaliana. Genes Dev. 2006, 20, 3407-3425. [CrossRef]

57. He, X.F.; Fang, Y.Y.; Feng, L.; Guo, H.S. Characterization of conserved and new microRNAs and their targets, including a TuMV-induced TIR-NBS-LRR class R gene-derived new miRNA in Brassica. FEBS Lett. 2008, 582, 2445-2452. [CrossRef]

58. Arenas-Huertero, C.; Pérez, B.; Rabanal, F.; Blanco-Melo, D.; De la Rosa, C.; Estrada-Navarrete, G.; Sanchez, F.; Covarrubias, A.A.; Reyes, J.L. Conserved and novel miRNAs in the legume Phaseolus vulgaris in response to stress. Plant Mol. Biol. 2009, 70, 385-401. [CrossRef] [PubMed]

59. Griffiths-Jones, S.; Grocock, R.J.; van Dongen, S.; Bateman, A.; Enright, A.J. miRBase: microRNA sequences, targets and gene nomenclature. Nucleic Acids Res. 2006, 34, D140-D144. [CrossRef] [PubMed]

60. Griffiths-Jones, S.; Saini, H.K.; van Dongen, S.; Enright, A.J. miRBase: Tools for microRNA genomics. Nucleic Acids Res. 2008, 36, 154-158. [CrossRef] [PubMed]

61. Fahlgren, N.; Howell, M.D.; Kasschau, K.D.; Chapman, E.J.; Sullivan, C.M.; Cumbie, J.S. High-throughput sequencing of Arabidopsis microRNAs: Evidence for frequent birth and death of MIRNA genes. PLoS ONE 2007, 2, e219. [CrossRef]

62. Moxon, S.; Jing, R.; Szittya, G.; Schwach, F.; Rusholme Pilcher, R.L.; Moulton, V. Deep sequencing of tomato short rnas identifies microRNAs targeting genes involved in fruit ripening. Genome Res. 2008, 18, 1602-1609. [CrossRef]

63. Qiu, D.; Pan, X.; Wilson, I.W.; Li, F.; Liu, M.; Teng, W. High throughput sequencing technology reveals that the taxoid elicitor methyl jasmonate regulates microRNA expression in chinese yew (Taxus chinensis). Gene 2009, 436, 37-44. [CrossRef]

64. Morin, R.D.; Aksay, G.; Dolgosheina, E.; Ebhardt, H.A.; Magrini, V.; Mardis, E.R. Comparative analysis of the small rna transcriptomes of Pinus contorta and Oryza sativa. Genome Res. 2008, 18, 571-584. [CrossRef]

65. Yang, L.; Mu, X.; Liu, C.; Cai, J.; Shi, K.; Zhu, W.; Yang, Q. Overexpression of potato miR482e enhanced plant sensitivity to Verticillium dahlia infection. J. Integr. Plant Biol. 2015, 57, 1078-1088. [CrossRef]

66. Ouyang, S.; Park, G.; Atamian, H.S.; Han, C.S.; Stajich, J.E.; Kaloshian, I.; Borkovich, K.A. MicroRNAs Suppress NB DomainGenes in Tomato That Confer Resistance to Fusarium oxysporum. PLoS Pathog. 2014, 10, e1004464. [CrossRef]

67. Campo, S.; Peris-Peris, C.; Siré, C.; Moreno, A.B.; Donaire, L.; Zytnicki, M.; Notredame, C.; Llave, C.; Segundo, B.S. Identification of a novel microRNA (miRNA) from rice that targets an alternatively spliced transcript of the Nramp6 (Natural resistance-associated macrophage protein 6) gene involved in pathogen resistance. New Phytol. 2013, 199, 212-227. [CrossRef]

68. Mica, E.; Piccolo, V.; Delledonne, M.; Ferrarini, A.; Pezzotti, M.; Casati, C. High throughput approaches reveal splicing of primary microRNA transcripts and tissue specific expression of mature microRNAs in Vitis vinifera. BMC Genom. 2009, 10, 558. [CrossRef]

69. Pantaleo, V.; Szittya, G.; Moxon, S.; Miozzi, L.; Moulton, V.; Dalmay, T. Identification of grapevine microRNAs and their targets using high throughput sequencing and degradome analysis. Plant J. 2010, 62, 960-976. [CrossRef]

70. Wang, C.; Shangguan, L.; Kibet, K.N.; Wang, X.; Han, J.; Song, C. Characterization of microRNAs identified in a table grapevine cultivar with validation of computationally predicted grapevine miRNAs by miR-RACE. PLoS ONE 2011, 6, e21259. [CrossRef]

71. Natarajan, B.; Kalsi, H.S.; Godbole, P.; Malankar, N.; Thiagarayaselvam, A.; Siddappa, S.; Thulasiram, H.V.; Chakrabarti, S.K.; Banerjee, A.K. MiRNA160 is associated with local defense and systemic acquired resistance against Phytophthora infestans infection in potato. J. Exp. Bot. 2018, 69, 2023-2036. [CrossRef] 
72. Floyd, S.K.; Bowman, J.L. Gene regulation: Ancient microRNA target sequences in plants. Nature 2004, 428, 485-486. [CrossRef] 73. Lu, S.; Sun, Y.H.; Shi, R.; Clark, C.; Li, L.; Chiang, V.L. Novel and mechanical stress-responsive MicroRNAs in Populus trichocarpa that are absent from Arabidopsis. Plant Cell 2005, 17, 2186-2203. [CrossRef] 